\title{
Assessment of Medical Staff Perspective toward Organizational Culture Safety at Primary Health Care -Almadina Almonwarra, Saudi Arabia
}

\author{
Manal Amer ${ }^{1}$, Dr. Abdulrhman Mosaad S. Alahmadi ${ }^{2}$, Dr. Abdalaziz Yahya A. Marwi ${ }^{3}$ \\ ${ }^{1}$ Assistant Professor, Cairo University, Al-Farabi College Jeddah, \\ General Practitioner, Faculty of Medicine, Umm Al-Qura University, Makkah \\ ${ }^{3}$ General Practitioner, Faculty of Medicine, Tiba University, Almadina Almonwarra
}

\begin{abstract}
Few studies exist concerning the assessment medical staff perspective toward organizational culture safety . The purpose of this article was to assess the medical staff perspective toward oorganizational cculture safety at Primary Health Care -Almadina Almonwarra, Saudi Arabia.
\end{abstract}

Keywords: Perspective, Primary Health Care, Organizational Culture Safety \& Culture safety

\section{Methods}

A descriptive research design was utilized in the current research. A total of 200 medical staff at selected eight Primary Health Care was given a structured questionnaire On March, 2016. They were asked to indicate their perspectives towards organizational culture safety. For each item concerning the culture safety of the organizational structure, the proportion of medical staff perspectives towards the organizational culture safety was calculated. Descriptive statistics like percentage was used to describe the findings using SPSS 20.

\section{Results}

The current research study objectives were to assess the medical staff perspective toward organizational culture safety. A total of 200 medical staff, from the selected Primary Health Care , were surveyed using a confidential questionnaire. The current study data revealed that the highest positive reply was in the item of Senior management has a clear picture of the risk associated with patient care $(93.5 \%)$, followed by the item of It is not hard for doctors hide serious mistakes. Furthermore, the item of senior management provides a climate that promotes patient safety represent (91.5\%), followed by the item of Individuals in my department are willing to report behavior which is unsafe for patient Care which revealed (91\%). Although on the other hand the lowest percentage was in the item of I am provided with adequate resources (personnel, budget, and equipment)to provide safe patient care which represent (78.5\%) of positive reply toward the related safety culture. Conclusions. Concerning the medical staff perspective toward the organizational culture safety within the study setting, the data findings showed that; there was a highest level of positive feedback from the medical staff in relation to the organizational safety culture.

\section{Introduction}

Safety culture is a major determinant of safety for health care organizations. Safety culture has been formally adopted as a required element of nuclear power safety by the International Atomic Energy Agency. The theoretical assemble of a culture of safety has been applied to many domains. While debate continues over precisely what components are needed for such a culture of safety, several are commonly accepted as being crucial. (Roberts, 2005)

According to Gaba, (2000), to a great extent the literature on general patient safety that refers to "safety culture" merely uses it as a synonym for encouraging data collection and reporting, reducing blame, getting leadership involved, focusing on systems. Activities described in the literature as interventions to address safety culture characteristically have been functional in a single establishment and did not actually measure safety culture before or after implementation.

Concerning the safety measures the universal precaution is the main strategy so that all these infections could be prevented. Attributable to their inadequate experience in performing invasive procedures, medical students are at particular risk of exposure to blood-borne pathogens (Chopra, et al., 2008). Medical students should have satisfactory knowledge and skills in relation to adherence to personnel protective equipments before their initial training period at hospital which is a vital requirement for compliance. Furthermore, Elliott et al. (2005), reported that dedicated training must be conducted before a medical student carried out any patient procedure especially the ones concerning sharp devices. Physicians' compliance towards the personnel protective equipments has been reported to be with low rate.(Piotrowsk\& Hinshaw , 2002).

The terms 'primary care' and 'primary health care' are used in many different ways. In this paper the scope used has been selected to align with the National Primary Health Care Strategy, and encompasses services delivered by GPs,

Volume 6 Issue 1, January 2017 


\section{International Journal of Science and Research (IJSR) \\ ISSN (Online): 2319-7064 \\ Index Copernicus Value (2015): 78.96 | Impact Factor (2015): 6.391}

nurses, allied health providers, Aboriginal health practitioners and pharmacists both within the public and private sectors . (Krumberger \& Building,2001) .Safety Culture compromise practices that the medical and paramedical staff applied to protect themselves, patients \& patients families from the hazards caused by non compliance to personnel protective equipments by the health care providers , statistics reported by the Central Register of Occupational Diseases in Poland indicates that among 314 new cases of occupational diseases in HCWs in 2005, HBV and HCV represented $42.6 \%$ of all cases.। Despite the substantial reduction in $\mathrm{HBV}$ infection since vaccination was introduced in 1989, the incidence of HCV hepatitis in Poland is still on the increase in this occupational group. (Welsh, Pedot \& Anderson, 2010).

There are a large number of organizations that have a role in quality and safety in primary health care in Australia, and many programs and initiatives are in place to improve care provided in this sector. One of these organizations is the Australian Commission on Safety and Quality in Health Care (the Commission), which was established in 2005 to lead and coordinate improvements in safety and quality nationally.( Ciavarelli, Figlock \& Sengupta, 2009).

\section{Methods}

A descriptive research design was utilized in the current research. A total of 200 medical staff of selected 8 primary health care, Almadina Almonwarra , Saudi Arabia, were given a structured questionnaire during March 2016.This number constitute, more than two third of the medical staff of the time of data collection. All wards representing units concerning all the subspecialties' were consider as a setting for the current research. The medical staff at each unit was contacted to discuss the importance of the research and the study protocol. An anonymous 10-items questionnaire was adopted from valid \& reliable tool using the guidelines from a Taxonomy used in the TAPS study, including distribution of the 525 patient safety incidents identified in the study from 415 incident reports received for Augustine (1993). All questions had fixed answer categories.

The questionnaire was pilot-tested and dealt with the following topics: demographic data; data concerning the organization items of culture safety. Descriptive statistics like percentage was used to describe the findings using SPSS 20. All categories data were analyzed using the Chisquared test with or without Yates' correction; Statistical significance for all analyses was presumed for $\mathrm{P}$ at 0.05 .

For the purposes of comparing female \& male interns, we grouped all interns based on gander classification. Since occupational experiences had not been organized in a systematic manner for educational purposes, we placed the term intervention in parentheses.

\section{Results}

The current research study objectives were to assess the medical staff perspective toward oorganizational cculture safety at Primary Health Care-Almadina Almonwarra, Saudi Arabia. A total of 200 medical staff, from the selected setting, were surveyed using a confidential questionnaire. The results indicated that the medical staff perspective toward the organizational culture safety within the study setting, the data findings showed that; there was a highest level of positive feedback from the medical staff in relation to the organizational safety culture. Specifically, the current study data revealed that the highest positive reply was in the item of Senior management has a clear picture of the risk associated with patient care (93.5\%) , followed by the item of It is not hard for doctors hide serious mistakes. Furthermore, the item of Senior management provides a climate that promotes patient safety represent (91.5\%) , followed by the item of Individuals in my department are willing to report behavior which is unsafe for patient Care which revealed (91\%). Although on the other hand the lowest percentage was in the item of I am provided with adequate resources (personnel, budget, and equipment)to provide safe patient care which represent (78.5\%) of positive reply toward the related safety culture.

Table 1: Perspective of Medical Staff toward Organizational culture Safety

\begin{tabular}{|c|c|c|c|c|}
\hline \multirow{2}{*}{ Items of Organizational Culture } & \multicolumn{2}{|c|}{ Yes } & \multicolumn{2}{|c|}{ No } \\
\cline { 2 - 5 } & No & $\%$ & No & $\%$ \\
\hline $\begin{array}{c}\text { Loss of experienced personnel has } \\
\text { negatively affected my ability to } \\
\text { provide high quality patient care }\end{array}$ & 163 & 81.5 & 37 & $18.5 \%$ \\
\hline $\begin{array}{c}\text { I am provided with adequate resources } \\
\text { (personnel, budget, and equipment) to } \\
\text { provide safe patient care }\end{array}$ & 157 & 78.5 & 43 & 21.5 \\
\hline $\begin{array}{c}\text { It is not hard for doctors to hide serious } \\
\text { mistakes }\end{array}$ & 186 & 93.0 & 14 & 7.0 \\
\hline $\begin{array}{c}\text { Senior management has a clear picture } \\
\text { of the risk associated with patient care }\end{array}$ & 187 & 93.5 & 13 & 6.5 \\
\hline $\begin{array}{c}\text { Senior management has a good idea of } \\
\text { the kinds of mistakes that actually occur } \\
\text { in this facility }\end{array}$ & 178 & 89.0 & 22 & 11.0 \\
\hline $\begin{array}{c}\text { Good communication flow exists up the } \\
\text { chain of command regarding patient } \\
\text { safety issues }\end{array}$ & 169 & 84.5 & 31 & 15.5 \\
\hline $\begin{array}{c}\text { Patient safety decisions are made at the } \\
\text { proper level by the most qualified } \\
\text { people }\end{array}$ & 179 & 89.5 & 21 & 10.5 \\
\hline $\begin{array}{c}\text { Senior management provides a climate } \\
\text { that promotes patient safety }\end{array}$ & 183 & 91.5 & 17 & 8.5 \\
\hline $\begin{array}{c}\text { Senior management considers patient } \\
\text { safety when program changes are } \\
\text { discussed }\end{array}$ & 174 & 87.0 & 26 & 13.0 \\
\hline $\begin{array}{c}\text { Individuals in my department are } \\
\text { willing to report behavior which is } \\
\text { unsafe for patient care }\end{array}$ & 182 & 91.0 & 18 & 9.0 \\
\hline
\end{tabular}

Concerning the medical staff perspective toward the organizational culture safety within the study setting, the data findings showed that; there was a highest level of positive feedback from the medical staff in relation to the organizational safety culture . Specifically , the current study data revealed that the highest positive reply was in the item of Senior management has a clear picture of the risk associated with patient care (93.5\%), followed by the item of It is not hard for doctors hide serious mistakes. Furthermore, the item of senior management provides a climate that promotes patient safety represent (91.5\%) , followed by the item of Individuals in my department are willing to report behavior which is unsafe for patient Care

\section{Volume 6 Issue 1, January 2017




\section{International Journal of Science and Research (IJSR) \\ ISSN (Online): 2319-7064}

Index Copernicus Value (2015): 78.96 | Impact Factor (2015): 6.391

which revealed (91\%). Although on the other hand the lowest percentage was in the item of I am provided with adequate resources (personnel, budget, and equipment)to provide safe patient care which represent (78.5\%) of positive reply toward the related safety culture.

\section{Discussion}

The response rate to the current research was excellent, suggesting that this was an area of importance for medical staff. In this research, more than two third of the medical staff were replied that there was a high positive perspective toward organizational culture safety compared to a study conducted by Ciavarelli, Figlock \& Sengupta who studied the organizational factors in aviation accidents it revealed that the hospital staff reported (46\%) of the medical staff in relation to organizational culture safety. Moreover, In Saudi Arabia, it was reported that there was a lack of skills in relation to utilization of the safety culture at primary level of care which reported by (Hesse, et al., 2006). This was partially explained by the deficiency of the curricular content of medical and nursing schools in Saudi Arabia , in the relation to all the elements of organizational safety culture (Weingart, Ship \& Aronson). As well as, according to Vaughan , (2004), much of the existing information about patient safety risks in primary health care settings comes from research about reported errors and incidents, including studies that have attempted to develop taxonomies to classify the types of errors and incidents that occur in these settings. These types of studies are generally based on voluntary anonymous or confidential self-reports, and to date have been limited to general practice settings.

Furthermore, this research results is congruent with the results of Dhaliwal, et al., (2011), who reported that A number of studies have attempted to estimate the size of the patient safety problem in primary care, usually by counting the number of reported incidents. This has provided a wide range of results, with early studies reporting rates ranging from five to 80 incidents per 100,000 consultations.20 The TAPS study calculated the incidence of reported incidents based on the number of Medicare item numbers billed and the number of individual patients seen.28 The incidence of reported patient safety incidents per Medicare patient encounter item per year was $0.078 \%$ (or one for every 1282 items billed), and the incidence of reported patient safety incidents per patient seen per year was $0.24 \%$ (or one for every 417 patients seen).

Additionally, Another study examined the identification of patients incidents prospectively, and GPs were asked to identify after each consultation whether certain events had occurred (such as missing investigation results, misdiagnosis or communication problems with the patient). Of the 351 patient visits for which data was recorded, 83 (24\%) were associated with the occurrence of a patient safety incident, and 117 separate incidents were identified in these visits.

\section{Conclusions}

Concerning the medical staff perspective toward the organizational culture safety within the study setting, the data findings showed that; there was a highest level of positive feedback from the medical staff in relation to the organizational safety culture . Specifically, the current study data revealed that the highest positive reply was in the item of Senior management has a clear picture of the risk associated with patient care $(93.5 \%)$, followed by the item of It is not hard for doctors hide serious mistakes. Furthermore, the item of senior management provides a climate that promotes patient safety represent (91.5\%), followed by the item of Individuals in my department are willing to report behavior which is unsafe for patient Care which revealed (91\%). Although on the other hand the lowest percentage was inthe item of I am provided with adequate resources (personnel, budget, and equipment) to provide safe patient care which represent (78.5\%) of positive reply toward the related safety culture.

We recommend wider implementation, evaluation and improvement of training of the medical and paramedical staff in relation to all elements of organizational safety culture and standardized aspects of patient safety.response rate to the questionnaire means that the results of this study are likely to reflect accurately the situation regarding the application of the aspects of organizational culture safety.

There is a need to consider factors that enable medical staff and other health care providers to utilize all the elements of organizational safety culture. Furthermore, while the focus on patient safety in primary health care is strengthening, the evidence base about effective patient safety solutions in this context is limited. Many similar approaches that are used in the acute care sector have also been discussed in primary health care settings. These include involvement of primary care providers in incident reporting and analysis of systems, use of information technology, and education about patient safety, improving communication and team work and supporting patient self management. To date evaluation of the effectiveness of these solutions in primary health care has been limited.

\section{Funding}

No funding sources

\section{Conflict of interest}

None declared

\section{Ethical Approval}

The study was approved by the Institutional Ethics Committee

\section{Acknowledgements}

Thanks to all the interns helps in performing the current research 


\section{International Journal of Science and Research (IJSR) \\ ISSN (Online): 2319-7064}

Index Copernicus Value (2015): 78.96 | Impact Factor (2015): 6.391

\section{References}

[1] Roberts KH. Cultural characteristics of reliability enhancing organizations. J Managerial Issues 2005;5:165-81.

[2] Gaba DM. Structural and organizational issues in patient safety: a comparison of health care to other high-hazard industries. California Management Rev 2000;43:83-102

[3] International Nuclear Safety Advisory Group: Basic Safety Principles for Nuclear Power Plants, Safety Series No. 75-INSAG-3. Vienna: IAEA, 1988.

[4] International Nuclear Safety Advisory Group: Safety Culture, Safety Series No. 75-INSAG-4. Vienna: IAEA, 1991.

[5] Roberts KH. Some characteristics of one type of high reliability organization. Organization Sci 1990;1:16076.

[6] Roberts KH, Rousseau DM, La Porte TR. The culture of high reliability: quantitative and qualitative assessment aboard nuclear powered aircraft carriers. J High Technol Manage Res 1994;5:141-61.

[7] Piotrowski MM, Hinshaw DB. The safety checklist program: creating a culture of safety in intensive care units. Jt Comm J Qual Improve 2002;28:306-15.

[8] Wong $\mathrm{P}$, Helsinger D, Petry J. Providing the right infrastructure to lead the culture change for patient safety. Jt Comm J Qual Improve 2002;28:363-72.

[9] Krumberger JM. Building a culture of safety. RN 2001;64:32ac2-32ac3.

[10] Sexton JB, Thomas EJ, Helmreich RL. Error, stress, and teamwork in medicine and aviation: cross sectional surveys. BMJ 2000;320:745-9.

[11] Shortell SM, Rousseau DM, Gillies RR, et al. Organizational assessment in intensive care units (ICUs): construct development, reliability, and validity of the ICU nurse-physician questionnaire. Med Care 1991;29:709-26.

[12] Shortell SM, Jones RH, Rademaker AW, et al. Assessing the impact of total quality management and organizational culture on multiple outcomes of care for coronary artery bypass graft surgery patients. Med Care 2000;38:207-17.

[13] Shortell SM, Zimmerman JE, Rousseau DM, et al. The performance of intensive care units: does good management make a difference? Med Care 1994;32:508-25.

[14] Zimmerman JE, Rousseau DM, Duffy J, et al. Intensive care at two teaching hospitals: an organizational case study. Am J Crit Care 1994;3:129-38.

[15]Zimmerman JE, Shortell SM, Rousseau DM, et al. Improving intensive care: observations based on organizational case studies in nine intensive care units: a prospective, multicenter study. Crit Care Med 1993;21:1443-51.

[16] Helmreich RL, Schaefer H. Team performance in the operating room. In: Bogner $\mathrm{M}$, ed. Human error in medicine. Hillsdale, NJ: Lawrence Earlbaum Associates, 1994: 225-53.

[17] Wakefield BJ, Blegen MA, Uden-Holman T, et al. Organizational culture, continuous quality improvement, and medication administration error reporting. Am J Med Qual 2001;16:128-34.
[18] Gaba DM, Howard SK, Jump B. Production pressure in the work environment: California anesthesiologists' attitudes and experiences. Anesthesiology 1994;81:488500.

[19] Ciavarelli A, Figlock R, Sengupta K. Organizational factors in aviation accidents. Naval Postgrad School Res 2009;9:4-5, 40-3.

[20] Ciavarelli A, Figlock R, Sengupta K, et al. Assessing organizational safety risk using questionnaire survey methods. 11th International Symposium on Aviation, Columbus, OH, 2001.

[21] Roberts KH. Managing high-reliability organizations. California Manage Rev 1990;32:101-13.

[22] Augustine $\mathrm{CH}$, Weick KE, Bagian JP, et al. Predispositions toward a culture of safety in a large multi-facility health system. Proceedings of Enhancing Patient Safety and Reducing Errors in Health Care, Rancho Mirage, CA, November 1998: 138-41.

[23] Shojania KG, Duncan BW, McDonald KM, et al, eds. Making health care safer: a critical analysis of patient safety practices. Evidence Report/Technology Assessment No. 43, AHRQ Publication No. 01-E058. Rockville, MD: Agency for Healthcare Research and Quality (AHRQ), 2001.

[24] Welsh CH, Pedot R, Anderson R. Use of morning report to enhance adverse event detection. J Gen Intern Med 2009;11:454-60.

[25] Weingart SN, Ship AN, Aronson MD. Confidential clinician-reported surveillance of adverse events among medical inpatients. J Gen Intern Med 2000;15:470-7.

[26]Dillman DA, Eltinge JL, Groves RM, et al. Survey nonresponse in design, data collection and analysis. In: Groves RM, Dillman DA, Eltinge JL, et al. Survey nonresponse. New York: John Wiley \& Sons, 2001: 326.

[27] Platek R, Gray GB. Imputation methodology. In: Incomplete data in sample surveys. Volume 2. Theory and bibliographies. New York: Academic Press, 1983: 255-94.

[28] Vaughan D. The Challenger launch decision. Chicago: University of Chicago Press, 2004: 238-77. 